\title{
Latent profiles of elite Malaysian athletes' use of psychological skills and techniques and relations with mental toughness
}

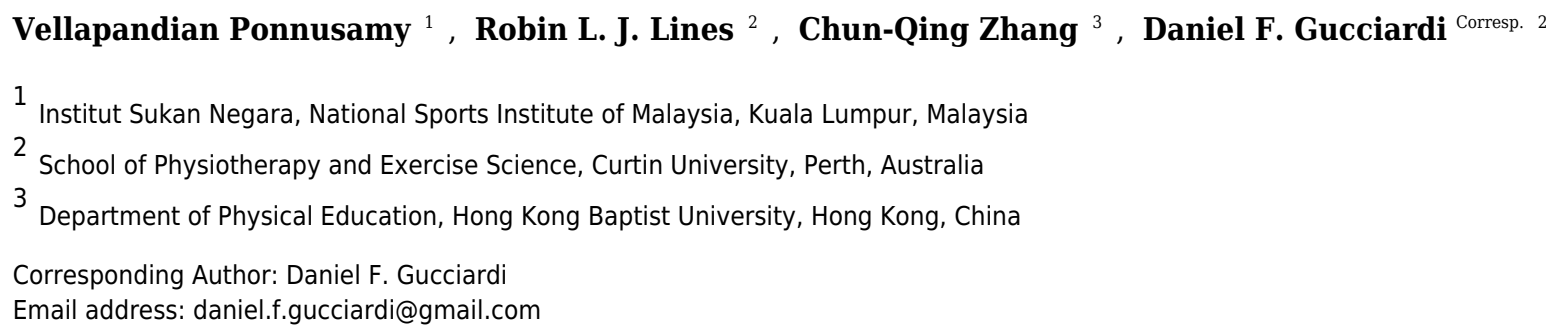

Background: The majority of past work on athletes' use of psychological skills and techniques (PSTs) has adopted a variable-centered approach in which the statistical relations among study variables are averaged across a sample. However, variable centered-analyses exclude the possibility that PSTs may be used in tandem or combined in different ways across practice and competition settings. With this empirical gap in mind, the purposes of this study were to identify the number and type of profiles of elite athletes' use of PSTs, and examine differences between these clusters in terms of their self-reported mental toughness Methods: In this cross-sectional survey study, 285 Malaysian elite athletes ( 170 males, 115 females) aged 15 to 44 years ( $M=18.89$, SD = 4.49) completed measures of various PSTs and mental toughness. Latent profile analysis was employed to determine the type and number of profiles that best represent athletes' reports of their use of PSTs in practice and competition settings, and examine differences between these classes in terms of self-reported mental toughness. Results: Our results revealed three profiles (low, moderate, high use) in both practice and competition settings that were distinguished primarily according to quantitative differences in the absolute levels of reported use across most of the PSTs assessed in practice and competition settings, which in turn, were differentially related with mental toughness. Specifically, higher use of PSTs was associated with higher levels of mental toughness. Conclusions: This study provides one of the first analyses of the different configurations of athletes' use of PSTs that typify unique subgroups of performers. An important next step is to examine the longitudinal (in) stability of such classes and therefore provide insight into the temporal dynamics of different configurations of athletes' use of PSTs. 
1 Running head: Profiles of psych skills usage

2

3

4

5

6

7

8

9

Latent profiles of elite Malaysian athletes' use of psychological skills and techniques and relations with mental toughness *Address correspondence to Daniel Gucciardi, School of Physiotherapy and Exercise 


\section{Abstract}

Background: The majority of past work on athletes' use of psychological skills and techniques (PSTs) has adopted a variable-centered approach in which the statistical relations among study variables are averaged across a sample. However, variable centered-analyses exclude the possibility that PSTs may be used in tandem or combined in different ways across practice and competition settings. With this empirical gap in mind, the purposes of this study were to identify the number and type of profiles of elite athletes' use of PSTs, and examine differences between these clusters in terms of their self-reported mental toughness

Methods: In this cross-sectional survey study, 285 Malaysian elite athletes (170 males, 115

37 females) aged 15 to 44 years $(\mathrm{M}=18.89, \mathrm{SD}=4.49)$ completed measures of various PSTs and mental toughness. Latent profile analysis was employed to determine the type and number of profiles that best represent athletes' reports of their use of PSTs in practice and competition settings, and examine differences between these classes in terms of self-reported mental toughness.

42 Results: Our results revealed three profiles (low, moderate, high use) in both practice and competition settings that were distinguished primarily according to quantitative differences in the

44 absolute levels of reported use across most of the PSTs assessed in practice and competition

45 settings, which in turn, were differentially related with mental toughness. Specifically, higher use 46 of PSTs was associated with higher levels of mental toughness. 
47 Conclusions: This study provides one of the first analyses of the different configurations of

48 athletes' use of PSTs that typify unique subgroups of performers. An important next step is to

49 examine the longitudinal (in) stability of such classes and therefore provide insight into the

50 temporal dynamics of different configurations of athletes' use of PSTs.

51

52

53

54 


\section{Latent profiles of elite Malaysian athletes' use of psychological skills and techniques and} relations with mental toughness
The development of psychological skills and techniques (PSTs) alongside the physical, technical and tactical aspects of sporting performance is considered a core feature of athlete development (Bergeron et al., 2015). Within sporting contexts, psychological skills encompass desired personal attributes such as optimism and self-efficacy that are central to high performance (i.e., the 'having' part). In contrast, psychological techniques capture the methods or processes by which individuals attain desired levels of personal attributes, such as self-talk and imagery (i.e., the 'doing' part). In other words, psychological skills are developmental targets that are addressed via training in psychological techniques (Vealey, 1988). Evidence supports the importance of several psychological skills (e.g., confidence; Moritz, Feltz, Fahrbach, Mack, 2000; Woodman \& Hardy, 2003) and techniques (Brown \& Fletcher, 2017; McCormick, Meijen, \& Marcora, 2015) for high performance among athletes. Unsurprisingly, psychological skills training represents core business for psychologists working in sport settings where high performance, innovation, and success are key (Adler et al., 2015; Harmison, 2011). Given this focus in applied practice, an important consideration for future work is understanding athletes' use of PSTs in practice and competition settings.

Much of the past work on usage of PSTs has compared successful athletes with their less successful counterparts, with a specific focus on usage patterns during training or practice (i.e., learning or applying skills or tactics in controlled environments) and within competition (i.e., when competing against other athletes). In a sample of US athletes who took part in the 2000 Olympic Games, discriminant function analysis revealed that medalists $(n=52)$ reported higher use of imagery, emotional control and automaticity in competition than non-medalists $(\mathrm{n}=124)$, 
78 whereas the skills and strategies of self-talk and emotional control distinguished these two 79 groups of performers in terms of practice settings (Taylor, Gould, \& Rolo, 2008). Within the context of rugby union, discriminant function analysis revealed that elite Japanese players $(\mathrm{n}=$ 95) reported in competition settings higher levels of goal setting, emotional control, relaxation, and activation, and lower scores of negative thinking when compared with university level players $(n=257)$; in contrast, goal setting, imagery and relaxation contributed most to these distinction between these two groups in terms of their usage within practice contexts (Tanaka \& Gould, 2015). Collectively, the findings of this body of work indicates that more successful athletes use PSTs more frequently than their less successful counterparts (Gould \& Maynard, 87 2009).

Despite what we have learned about athletes' use of PSTs in recent years, little is known about the different configurations of these developmental targets and methods that typify unique subgroups of performers. In particular, research in this area has been dominated by variablecentered approaches (e.g., regression and discriminant function analyses) that provide insight regarding the statistical relations among study variables averaged across a sample. An inherent assumption within variable-centered analyses where the unit of analysis is the concept or variable is that athletes' use of PSTs is homogenous and that all relations between variables generalize to the entire population (Bergman \& Trost, 2006). However, this assumption may be erroneous as the development and maintenance of PSTs typically incorporates both group-based and individualized components (for examples, see Dosil, 2006). With regard to self-talk, for example, practitioners need to consider individual differences in self-talk ability (e.g., low to high skill), cultural factors (e.g., individualistic versus collectivist cultures), and contextual dimensions (e.g., salience of difference forms of self-talk) for effective training (Van Raalte, 
101 Vincent, \& Brewer, 2017). Person-centered analyses enable researchers to capture the

102 heterogeneity of populations by identifying subgroups of individuals who share common patterns

103 of interacting characteristics (Bergman \& Trost, 2006). Applied to the study of athletes' use of

104 PSTs, the potential of a person-centered approach lies in the ability to address an important yet

105 unanswered question: are differences in athletes' use of PSTs quantitative (e.g., low, moderate,

106 or high frequency across all attributes and methods) or qualitative (e.g., low in some techniques,

107 high in others) in nature? In addressing this question, researchers can understand the

108 pervasiveness of subgroups who share common patterns in their use of PSTs, and the differential

109 relations between these profiles and hypothesized determinants and outcomes.

The second key extension offered in this study concerns the relations between unique

111 combinations or patterns of athletes' use of PSTs with mental toughness. Drawing from recent

112 advancements in theory and research (e.g., Gucciardi et al., 2015; Hardy, Bell, \& Beattie, 2014),

113 mental toughness has been conceptualized as a psychological resource that enables individuals to

114 attain and sustain goal-directed behavior despite varying degrees of situational demands that

115 range from everyday stressors to major adversities (for a review, see Gucciardi, in press).

116 Qualitative (Weinberg, Butt, Mellano, \& Harmison, 2017), longitudinal (Gucciardi et al., 2015)

117 and experimental research (Bell, Hardy, \& Beattie, 2014) suggests that mental toughness is state-

118 like in that it has properties that can vary or endure across situations and time, yet is open to

119 development and enhancement. Emerging evidence provides support for the significance of

120 mental toughness in terms of fostering high performance (e.g., Arthur, Fitzwater, Hardy, Beattie,

121 \& Bell, 2015; Mahoney, Gucciardi, Ntoumanis, \& Mallett, 2014; for a review, see Cowden,

122 2017) and maximising adaptive associations with important psycho-social factors such as

123 burnout (Madigan \& Nicholls, 2016), motivation and anxiety (Schaefer, Vella, Allen, \& Magee, 
124 2016). As such, effort has been directed towards understanding the key developmental

125 antecedents of mental toughness (for a review, see Anthony, Gucciardi, \& Gordon, 2016). Given

126 their moderate positive effect on sport performance (Brown \& Fletcher, 2017), it is unsurprising

127 that psychological techniques are considered essential tools in the toolbox of mentally tough

128 athletes (Jaescjke, Sachs, \& Dieffenbach, 2016; Weinberg et al., 2016) and therefore have been

129 the focus of intervention efforts (Fitzwater, Arthur, \& Hardy, 2018; Gucciardi, Gordon, \&

130 Dimmock, 2009). Consistent with theoretical perspectives of mental toughness as a salient

131 resource for stressful experiences (Gucciardi et al., 2015), common to this past work are

132 psychological techniques that enable individuals to coping with stressors and adversity (e.g.,

133 emotion regulation, arousal regulation, imagery). What remains unknown is the most effective

134 combination of PSTs for mental toughness. Clarifying this information will have important

135 implications for theory and practice. Substantively, it may be that one or two PSTs are most

136 salient in terms of their contribution to the explanation of mental toughness. If this finding is the

137 case, an analysis of the commonalities among these dominant PSTs might shed light on the

138 nature of mental toughness (e.g., primarily cognitive or emotion-based resource). From an

139 applied standpoint, this information would prove fruitful in guiding practitioners' focus for

140 psychological skills training programs.

141 As there are a variety of PSTs that are beneficial for athletic performance, it is important

142 that research is directed towards identifying groups of individuals who share similar

143 configurations or patterns of use and understanding the antecedents and outcomes of such

144 profiles. In light of this unexplored area of research, the purposes of this study were to identify

145 the number and type of profiles of elite athletes' use of PSTs, and examine external validity

146 evidence of these clusters in terms of their relations with mental toughness. Given the absence of 
147 past research or theory on profiles of athletes' use of PSTs, this study was considered exploratory

148 and therefore no hypotheses regarding the number and type of latent profiles were proposed a

149 priori. In terms of differences between unique profiles according to athletes' use of PSTs, we

150 expect that profiles of athletes who report using a greater number of PSTs will have higher levels

151 of mental toughness. Which specific combination of PSTs would be most adaptive in terms of

152 differences in self-reported mental toughness was not hypothesised a priori.

\section{Methods and Materials}

\section{Participants}

In total, 285 Malaysian elite athletes took part in this study (170 males, 115 females). The

term elite is used here to characterise both 'semi-elite' (e.g., involved in talent development

programs or selected to represent Malaysia) and 'competitive elite' (e.g., top tier competitive

league internationally) athletes in terms of their standard of performance, success, experience, and competiveness of sport within Malaysia and the world (Swann, Moran, \& Piggott, 2015).

Athletes were recruited from national squads across a variety of team (e.g., field hockey, bola sepak) and individual sports (e.g., shooting, archery, taekwondo). At the time of data collection, participants were aged 15 to 44 years $(M=18.89, \mathrm{SD}=4.49)$, had between 1 and 20 years of experience in their sport $(\mathrm{M}=4.28, \mathrm{SD}=3.38)$, and completed between 2 and 15 training sessions per week $(M=6.00, \mathrm{SD}=2.14)$.

Measures

We measured mental toughness using a unidimensional, 8-item tool (Gucciardi et al., 167 2015). Participants were asked to indicate how true each of the statements (e.g., "I strive for continued success" and "I am able to regulate my focus when performing tasks") are an indication of how they typically think, feel, and behave as an athlete using a 7-point response 
170 scale $(1=$ false, $100 \%$ of the time to $7=$ true, $100 \%$ of the time $)$. The 68 -item test of performance

171 strategies (TOPS; Hardy et al., 2010) was employed to measures athletes' use of several PSTs in

172 training (goal setting, self-talk, imagery, attention control, emotional control, activation,

173 relaxation, automaticity) and competition (goal setting, self-talk, imagery, negative thinking,

174 emotional control, activation, relaxation, automaticity, attentional control). Participants were

175 asked to rate how frequently a range of situations applies to them in training and competition

176 (e.g., "I keep my thoughts positive during competitions" and "I visualize my competition going

177 exactly the way I want it to go") using a 5-point response scale $(1=$ never, $2=$ rarely, $3=$

178 sometimes, 4 = often, 5 = always). Both tools were translated from English into Malay using

179 forward- and back-translation procedures by an independent translator at both stages of the

180 process (Hambleton \& Kanjee, 1995).

181 Procedures

182 After obtaining ethical approval from the Human Research Ethics Committee of the corresponding author's institution (HR176/2013), we contacted the high performance manager of each sport or head coach of individual teams to provide details on the aims and procedures of the study, and request permission to approach coaches and athletes. Managers and coaches who expressed an interest in participating liaised with the first author to organize a convenient time and location to distribute the survey package to the athletes in person. Consenting athletes (and their parents when aged under 18 years) completed the survey package either at the training venue prior to, or after a practice session; in situations where the time demands of a training session could not accommodate the former method, athletes took the survey home with them, completed it, and returned it at the next training session.

\section{Statistical Analyses}


194 Lanza, Tan, \& Bray, 2013), we conducted the primary analyses in two phases. First, we used

195 latent profile analysis (LPA) with a robust maximum likelihood estimator (MLR) to determine

196 the type and number of profiles that best represent athletes' reports of their use of PSTs during

197 practice and competition. Aligned with an inductive approach, we first specified two profiles and

198 sequentially increased the number of latent profiles until we arrived at the class structure that

199 represented an optimal balance between model fit and parsimony (Nylund, Asparouhov, \&

200 Muthén, 2007). Model comparisons were assessed using a combination of relative fix indices

201 (Akaike Information Criteria [AIC], Bayesian Information Criteria [BIC] and its sample size

202 adjusted version $[\mathrm{ABIC}]$ ), ratio test (Lo-Mendell-Rubin likelihood [LMR]), and an indicator of

203 the clarity of class allocation (entrophy). The best model is one that has the lowest value for

204 relative fit indexes, entrophy values that are closest to 1 and larger in comparison to other class

205 structures, and statistically significant ratio test (Berlin, Williams, \& Parra, 2014; Nylund,

206 Asparouhov, \& Muthén, 2007). These statistical criteria were considered alongside an

207 examination of the distinctiveness of solutions and sample size within each cluster (Lubke \&

208 Neale, 2006). Second, we examined age, sex $(0=$ female, $1=$ male $)$, and years playing

209 experience as determinants of latent profile membership, and mental toughness as an outcome of

210 membership within an LPA framework. The R3STEP and DU3STEP commands were used to

211 model age, sex, and playing experience and mental toughness as an auxiliary outcome using the

212 3-step method (Asparouhov \& Muthén, 2013). The 3-step procedure first determines the latent

213 classes based on the proposed indicator variables, then classifies participants, and finally relates

214 this classification to covariates, determinants or distal outcomes. Coefficient $H$ provided an

215 estimate of construct reliability evidence, with a value of $\geq .80$ considered desirable (Hancock \& 
216 Mueller, 2001). All analyses were performed using Mplus 7.4 (Muthén \& Muthén, 2015) using

217 full information maximum likelihood (FIML) to make use of all available data.

218

219

220

221

222

223

224

225

226

227

228

229

230

231

232

233

234

235

236

237

238

\section{Results}

Data screening procedures indicated the study variables were normally distributed in the sample (i.e., skewness/kurtosis $>2)$, yet included three univariate outliers $(z> \pm 3.5)$; the

exclusion of these outliers did not alter the primary findings so they were retained for reporting purposes (Tabachnick \& Fidell, 2013). Descriptive statistics, internal reliability estimates and bivariate correlations among study variables are presented in Table 1. Several of the construct reliability estimates were below the recommended value of .80 (Hancock \& Mueller, 2001), so it is important to keep this evidence in mind when interpreting the results of the primary analyses. An overview of the statistical criteria employed to identify the optimal solution for practice and competition settings is detailed in Table 2. The results show that the 3-class model represents the optimal solution for both practice and competition settings. First, an examination of the percentage change values in relative fit indices (AIC, BIC, ABIC) presented in Table 2 indicates there is a steep decrease in models with two to three classes at which point the degree of improvement in model fit plateaued (Morin et al., 2011). Second, the 3-class model was the point at which the highest degree of classification accuracy was observed in competition settings (.89), and was among the highest for practice settings (.78). Finally, the average probability that participants were correctly classified in the given latent profile or misclassified provided additional evidence for the suitability of the 3-class solution in practice and competition settings (see Table 3). Thus, we retained the 3-profile solution for subsequent analyses.

An inspection of the estimated means indicated that differences between classes were primarily quantitative in nature (see Figures 1 and 2). In terms of practice settings, class 1 ( $\mathrm{n}=$ 
239 59) reported higher levels of all PSTs than both classes $2(n=72)$ and $3(n=154)$ except for

240 emotional control and automaticity; these latter two PSTs were comparable across all three

241 classes. In turn, class 2 reported higher levels than class 3 on all but these two PSTs. Similar

242 findings were observed in competition settings. With the exception of emotional control, class 1

$243(n=102)$ reported higher levels of positive psychological skills and lowest levels of negative

244 psychological skills (negative thinking) than both classes $2(n=25)$ and $3(n=158)$; similar

245 findings were observed for the comparison of class 2 with class 3 . As such, we labelled class 1 as

246 'high adaptive use', class 2 as 'moderate adaptive use' and class 3 and 'low adaptive use' of

247 PSTs.

248 Age, sex, and years playing experience were examined as determinants of latent profile

249 membership (see Table 4). With regard to practice settings, older athletes and those with greater

250 playing experience in their sport were less likely to be in the high adaptive use and low adaptive

251 use profiles when compared with the moderate adaptive use profile. Within competition settings,

252 male athletes were less likely to be in the high adaptive use profile when compared with the

253 moderate use profile. Additionally, older athletes were more likely to be in the low used profile

254 when compared with the moderate use profile.

255

We subsequently tested the degree to which these classes differed on mental toughness.

256 With regard to practice settings, mental toughness differed as a function of class membership.

257 High adaptive PSTs use athletes $(M=6.48, S D=.38)$ reported significantly $(p<.001)$ higher

258 levels of mental toughness than athletes classed within the moderate adaptive $(M=5.88, S D=$

$259.74, d=1.02)$ and low adaptive PSTs use groups $(M=5.21, S D=.18, d=1.45)$; the difference in

260 mental toughness between the moderate and low adaptive PSTs use groups was also significant

$261(p<.001, d=.69)$. Similar results were obtained in competition settings, whereby mental 
262 toughness differed as a function of class membership. High PSTs use athletes $(M=6.36, S D=$

$263.71)$ reported significantly $(p<.001)$ higher levels of mental toughness than the moderate $(M=$

$2645.61, S D=.88, d=.94)$ and low PSTs use groups $(M=5.06, S D=1.05, d=1.45)$; the difference

265 in mental toughness between the moderate and low PSTs use groups was also significant $(p=$ $266.017, d=.57)$

267

268

269

270

271

272

273

274

275

276

277

278

279

280

281

282

283

284

\section{Discussion}

Using a person-centered approach to investigate athletes' use of PSTs in practice and competition settings, we identified the existence of distinct profiles or subgroups of athletes who share similarities in their reported frequency. Overall, our results revealed three profiles in both practice and competition settings that were distinguished primarily according to quantitative differences in the absolute levels of reported use across most of the PSTs assessed, which in turn, were differentially related with mental toughness.

As the predominant analytical approach in past work (Tanaka \& Gould, 2015; Taylor, Gould, \& Rolo, 2008), variable centered-analyses exclude the possibility that PSTs may be used in tandem or combined in different ways across practice and competition settings. Our focus on uncovering different configurations of athletes' use of PSTs that typify unique subgroups of performers has shed light on a key substantive issue. Our results indicated that differences in athletes' reported use of PSTs are primarily quantitative in nature, that is, they vary in the absolute level of each developmental target and method within practice and competition settings. In terms of prevalence data, the majority of athletes were classified as moderate users of PSTs in practice (54\%) and competition (55\%) settings. The proportion of athletes classified as high users of PSTs was greater in competition settings (36\%) when compared with practice (21\%), with the prevalence of athletes profiled as low users of PSTs was lower in competitions (9\%) 
285 versus practice settings (25\%). That the majority of athletes in this study reported moderate-to-

286 high use of PSTs in practice and competition is unsurprising, given their positive effects on sport

287 performance (Brown \& Fletcher, 2017; McCormick, Meijen, \& Marcora, 2015) and the elite

288 status of the sample. Across both practice and competition settings, the largest differences

289 between classes in absolute use scores were observed for goal setting, self-talk, imagery,

290 activation, and relaxation. Substantively, these PSTs are primarily cognitive (e.g., imagining

291 alternative performance strategies) and arousal-focused (e.g., psyching oneself up/down for

292 competition) in nature. An important next step is to examine the longitudinal (in)stability of such

293 classes and therefore provide insight into the temporal dynamics of different configurations of

294 athletes' use of PSTs.

295 We assessed external validity evidence of these classes of differing use of PSTs in terms

296 of their relations with mental toughness. Only one study to date has examined the associations

297 between mental toughness and athletes' use of several PSTs. Correlational analyses of a sample

298 of 107 university or county level athletes revealed positive associations between mental

299 toughness and self-talk, emotional control, goal setting, relaxation, and activation $(.24<r>.37)$,

300 and an inverse relation with negative thinking (-.47) within competition (Crust \& Azadi, 2010).

301 For practice settings, total mental toughness was associated with automaticity, emotional control,

302 relaxation and self-talk $(.24<r>35)$. In contrast, we observed primarily moderate associations

303 between mental toughness and athletes' use of all PSTs in practice and competition settings (see

304 Table 1). One explanation for this discrepancy is that we sampled elite athletes only who have

305 greater access to psychological servicing through the national institute of sport. The bivariate

306 associations between mental toughness and PST use observed in the current study are broadly

307 consistent with qualitative work in which scholars have emphasised the importance of teaching 
308 athletes techniques to cope with stress and adversity (e.g., Jaescjke et al., 2016; Powell \&

309 Myers, 2017; Weinberg et al., 2016), most of which are captured in the TOPS. A key

310 consideration for psychological skills training is the simulation of stressors and adversities to

311 provide athletes with opportunities to test out different techniques (Weinberg, Freysinger, \&

312 Mellano, 2018). Our findings provide indirect support for this assertion in that the associations

313 between mental toughness and PST use were similar across practice and competition settings.

314 With regard to the results of the person-centered analyses, there were salient distinctions

315 in mean levels of mental toughness between the three classes that confirmed the quantitative

316 nature of the differences in the configurations of athletes' use of PSTs. Specifically, the high

317 PSTs use class reported the highest levels of mental toughness; the low PSTs use class reported

318 the lowest levels of mental toughness; and the moderate PSTs use class reported mental

319 toughness levels between these two classes. Broadly, these findings are consistent with past

320 intervention work in which athletes who have received psychological skills training packages

321 including multiple techniques have evidenced increases in their mental toughness (Fitzwater et

322 al., 2018; Gucciardi et al., 2009). An examination of the variability in mental toughness scores

323 provides further support for this substantive finding, such that the least amount of variation was

324 observed in the high PSTs use class and the most variation in the low use class. Collectively,

325 these findings shed light on the nature of mental toughness and suggest that it may best be

326 conceptualized as a resource that is characterized by cognitive and motivational factors. The

327 broad use of multiple PSTs for athletes with high levels of mental toughness suggests that they

328 have at their disposal a greater repertoire of techniques from which to draw to manage the

329 various stressors and adversities within their performance environment. Equally, it could also be

330 that greater PST use is an outcome of high mental toughness. Determining the causal 
331 characteristics between mental toughness and PSTs remains an important avenue for future

332 research.

Key strengths of this study include a modest sample of elite athletes, direct test of the

334 hypothesis that PSTs may be used in tandem or combined in different ways across practice and 335 competition settings, and incorporation of error in profile classification for the examination of

336 differences in mental toughness between the latent classes. Nevertheless, there are several

337 limitations of the current study that might motivate future research. First, a limitation of the

338 TOPS is that it measures the frequency of athletes' use of PSTs only and therefore excludes

339 information regarding the effectiveness of their implementation or utilization. As the majority of

340 PSTs assessed with the TOPS are primarily cognitive and arousal-based in nature, it is also

341 important to consider additional measures that capture emotionally-salient PSTs. Second, our

342 focus on Malaysian elite athletes means it is important that future research examines the extent to

343 which these findings generalize to other cohorts of athletes (e.g., culture), and test the invariance

344 of latent profiles across different subgroups (e.g., sex, sport type; Olivera-Aguilar \& Rikoon, in

345 press). Third, we relied on one outcome variable to assess external validity evidence of the latent

346 profiles. Future research could expand on our efforts to focus on a variety of antecedent (e.g.,

347 contextual, social or organizational factors) and outcome (e.g., decision-making, perceptions of

348 stress) variables, which could include both subjective assessments from the self or informants

349 (e.g., coaches) and objective performance data.

\section{Conclusion}

351

The burgeoning literature on PSTs among elite athletes has been limited by the

352 dominance of variable-centered analyses that do not account for the unique ways in which

353 athletes may use multiple skills or methods in conjunction with each other. By adopting an 
354 alternative, person-centered approach, this study offers several contributions to theoretical and 355 applied perspectives on athletes' use of PSTs and their relations with mental toughness, namely, 356 the use of PSTs is primarily quantitative in nature, and that classes with more frequent use report 357 higher levels of mental toughness. 


\section{References}

359 Adler AB, Bliese PD, Pickering MA, Hammermeister J, Williams J, Harada C, Csoka L,

360

361

362

363

364

365

366

367

368

369

370

371

372

373

374

375

376

377

378

379

Holliday B, Ohlson C. 2015. Mental skills training with basic combat training soldiers: a group randomized trial. Journal of Applied Psychology, 100: 1752-1764. doi: $10.1037 /$ ap10000021

Anthony DR, Gucciardi DF, Gordon S. 2016. A meta-study of qualitative research on mental toughness development. International Review of Sport and Exercise Psychology, 9: 160190. doi: 10.1080/1750984X.2016.1146787

Asparouhov T, Muthén B. 2013. Auxiliary variables in mixture modeling: A 3-step approach using Mplus. Mplus Web Notes, 15. Available at http://ww.statmodel.com/examples/webnotes

Arthur CA, Fitzwater J, Hardy L, Beattie S, Bell J. 2015. Development and validation of a military training mental toughness inventory. Military Psychology, 27: 232-241. doi: $10.1037 / \mathrm{mil} 0000074$

Bell JJ, Hardy L, Beattie S. 2014. Enhancing mental toughness and performance under pressure in elite young cricketers: a 2-year longitudinal intervention. Sport, Exercise and Performance Psychology, 2: 281-297. doi: 10.1037/a0033129

Bergeron MF, Mountjoy M, Armstrong N, Chia M, Cote J, Emery CA, Faigenbaum A, Hall Jr G, Kriemler S, Leglise M, Malina RM, Pensgaard AM, Sanchez A, Soligard T, SundgotBorgen J, van Mechelen W, Weissensteiner JR, Engebretsen L. 2015. International Olympic Committee consensus statement on youth athletic development. British Journal of Sports Medicine, 49: 843-851. doi: 10.1136/bjsports-2015-094962 
380

381

382

383

384

385

386

387

388

389

390

391

392

393

394

395

396

397

398

399

400

401

Bergman LR, Trost K. 2006. The person-oriented versus the variable-oriented approach: are they complementary, opposites, or exploring different worlds? Merrill-Palmer Quarterly, 52: 601-632.

Berlin KS, Williams NA, Parra GR. 2014. An introduction to latent variable mixture modeling (part 1): overview and cross-sectional latent class and latent profile analyses. Journal of Pediatric Psychology, 39: 174-187. doi: 10.1093/jpepsy/jst084

Brown DJ, Fletcher D. 2017. Effects of psychological and psychosocial interventions on sport performance: a meta-analysis. Sports Medicine, 47: 77-99. doi: 10.1007/s40279-016-05527

Cowden RC. 2017. Mental toughness and success in sport: a review and prospect. The Open Sports Science Journal, 10: 1-14. doi: 10.2174/1875399X01710010001

Crust L, Azadi K. 2010. Mental toughness and athletes' use of psychological strategies. European Journal of Sport Science, 10: 43-51. doi: 10.1080/17461390903049972

Dosil J. 2006. The sport psychologist's handbook: a guide for sport-specific performance enhancement. New Jersey: Wiley.

Fitzwater JPJ, Arthur CA, Hardy L. 2018. “The tough get tougher”: Mental skills training with elite military recruits. Sport, Exercise and Performance Psychology, 7: 93-107. doi: $10.1037 /$ spy0000101

Gould D, Maynard I. 2009. Psychological preparation for the Olympic Games. Journal of Sports Sciences, 27: 1393-1408. doi: 10.1080/02640410903081845

Gucciardi DF. in press. Mental toughness: Taking stock and considering new horizons. In G. Tenenbaum \& R. C. Eklund (Eds.), Handbook of sport psychology (4 ${ }^{\text {th }}$ ed.). Wiley. 
402 Gucciardi DF. 2017. Mental toughness: progress and prospects. Current Opinion in $403 \quad$ Psychology, 16: 17-23. doi: 10.1016/j.copsyc.2017.03.010

404 Gucciardi DF, Gordon S, Dimmock JA. 2009. Evaluation of a mental toughness training 405 program for youth-aged Australian footballers: I. a quantitative analysis. Journal of 406 Applied Sport Psychology, 21: 307-323. doi: 10.1080/10413200903026066

407 Gucciardi DF, Hanton S, Gordon S, Mallett CJ, Temby P. The concept of mental toughness: 408 Tests of dimensionality, nomological network, and traitness. Journal of Personality, 83: 26-44 .doi: 10.1111/jopy.12079

410

411

412

413

414

415

416

417

418

419

420

421

422

423

424

Hambleton RK, Kanjee, A. 1995. Increasing the validity of cross-cultural assessments: use of improved methods for test adaptations. European Journal of Psychological Assessment, 11: 147-157. doi: 10.1027/1015-5759.11.3.147

Hancock GR, Mueller RO. 2001. Rethinking construct reliability within latent variable systems. In Cudeck R, Du Toti S, Sorbom D,eds. Structural equation modeling: past and present. A festschrift in honor of Karl G. Jöreskog. Chicago: Scientific Software International, Inc, 195-216.

Hardy L, Roberts R, Thomas PR, Murphy SM. 2010. Test of Performance Strategies (TOPS): instrument refinement using confirmatory factor analysis. Psychology of Sport and Exercise, 11: 27-35. doi: 10.1016/j.psychsport.2009.04.007

Hardy L, Bell J, Beattie S. 2014. Preliminary evidence for a neuropsychological model of mentally tough behaviour. Journal of Personality, 82: 69-81. doi: 10.1111/jopy.12034

Harmison RJ. 2011. Peak performance in sport: identifying ideal performance states and developing athletes' psychological skills. Sport, Exercise and Performance Psychology, 1, 3-18. doi: 10.1037/2157-3905.1.S.3 
425 Jaescjke AM, Sachs M, Dieffenbach, K. 2016. Ultramarathon runners' perceptions of mental

426 toughness: A qualitative inquiry. The Sport Psychologist, 30: 242-255. doi:

427 10.1123/tsp.2014-0153

428

429

430

431

432

433

434

435

436

437

438

439

440

441

442

443

444

445

446

447 approach. Structural Equation Modeling, 20: 1-26. doi: 10.1080/10705511.2013.742377

Lubke GH, Neale MC. 2006. Distinguishing between latent classes and continuous factors: resolution by maximum likelihood. Multivariate Behavioral Research, 41: 499-532. doi: $10.1207 / \mathrm{s} 15327906 \mathrm{mbr} 4104 \_4$

Madigan DJ, Nicholls AR. 2016. Mental toughness and burnout in junior athletes: A longitudinal investigation. Psychology of Sport and Exercise, 32: 138-142. doi: 10.1016/j.psychsport.2017.07.002

Mahoney JW, Gucciardi DF, Ntoumanis N, Mallett CJ. 2014. Mental toughness in sport: Motivational antecedents and associations with performance and psychological health. Journal of Sport \& Exercise Psychology, 36: 281-292. doi: 10.1123/jsep.2013-0260

McCormick A, Meijen C, Marcora S. 2015. Psychological determinants of whole-body endurance performance. Sports Medicine, 45: 997-1015. doi: 10.1007/s40279-015-0319-6

Morin AJS, Maïano C, Nagengast B, Marsh HW, Morizot J, Janosz M. 2011. General growth mixture analysis of adolescents' developmental trajectories of anxiety: the impact of untested invariance assumptions on interpretations. Structural Equation Modeling, 18: 613648. doi: $10.1080 / 10705511.2011 .607714$

Moritz SE, Feltz DL, Fahrbach KR, Mack DE. 2000. The relation of self-efficacy measures to sport performance: a meta-analytic review. Research Quarterly for Exercise and Sport, 71: 280-294. doi: 10.1080/02701367.2000.10608908 
448 Muthén LK, Muthén B. Mplus users guide (7 $7^{\text {th }}$ ed.). Los Angeles CA: Muthén \& Muthén. 2015. 449 Available at: https://www.statmodel.com/download/usersguide/Mplus\%20Users\%20Guide\%20v6.pdf

451 Nylund KL, Asparouhov T, Muthén BO. 2007. Deciding on the number of classes in latent class

452

453

454

455

456

457

458

459

460

461

462

463

464

465

466

467

468

469

470

analysis and growth mixture modeling: a Monte Carlo simulation study. Structural

Equation Modeling, 14: 535-569. doi:10.1080/10705510701575396

Olivera-Aguilar M, Rikoon SH. in press. Assessing measurement invariance in multiple-group latent profile analysis. Structural Equation Modeling. doi:

$10.1080 / 10705511.2017 .1408015$

Powell AJ, Myers TD. 2017. Developing mental toughness: lessons from paralympians. Frontiers in Psychology, 8:1270. doi: 10.3389/fpsyg.2017.01270

Schaefer J, Vella SA, Allen MS, Magee CA. 2016. Competition anxiety, motivation, and mental toughness in golf. Journal of Applied Sport Psychology, 28: 309-320. doi:

$10.1080 / 10413200.2016 .1162219$

Swann C, Moran A, Piggott D. 2015. Defining elite athletes: Issues in the study of expert performance in sport psychology. Psychology of Sport \& Exercise, 16: 3-14. doi: 10.1016/j.psychsport.2014.07.004

Tabachnick BG, Fidell LS. 2013. Using multivariate statistics (6 ${ }^{\text {th }}$ ed.). Boston: Pearson.

Tanaka S, Gould D. 2015. Psychological skills usage among Japanese rugby players. International Journal of Sport and Exercise Psychology, 13: 309-319. doi: 10.1080/1612197X.2014.999344

Taylor MK, Gould D, Rolo C. 2008. Performance strategies of US Olympians in practice and competition. High Ability Studies, 19: 19-36. doi: 10.1080/13598130801980281 
471 Van Raalte JL, Vincent A, Brewer BW. 2017. Self-talk interventions for athletes: A theoretically 472 grounded approach. Journal of Sport Psychology in Action, 8: 141-151. doi:

473 $10.1080 / 21520704.2016 .1233921$

474 Vealey RS. 1988. Future directions in psychological skills training. The Sport Psychologist, 2:

475 318-336. doi: $10.1123 /$ tsp.2.4.318

476

477

478

479

480

481

482

483

484

485

486

487

488

Weinberg R, Butt J, Mellano K, \& Harmison R. 2017. The stability of mental toughness across situations: taking a social-cognitive approach. International Journal of Sport Psychology, 48: 280-302. doi: 10.7352/IJSP 2017.48.280

Weinberg R, Freysinger V, Mellano K. 2018. How can coaches build mental toughness? Views from sport psychologists. Journal of Sport Psychology in Action, 9: 1-10. doi: $10.1080 / 21520704.2016 .1263981$

Weinberg R, Freysinger V, Mellano K, Brookhouse E. 2016. Building mental toughness: perceptions of sport psychologists. The Sport Psychologist, 30: 231-241. doi: $10.1123 /$ tsp. $2015-0090$

Woodman T, Hardy L. 2003. The relative impact of cognitive anxiety and self-confidence upon sport performance: A meta-analysis. Journal of Sports Sciences, 21: 443-457. doi: $10.1080 / 0264041031000101809$ 


\section{Table $\mathbf{1}$ (on next page)}

Descriptive statistics, internal reliability, and correlations among study variables. 
Table 1. Descriptive statistics, internal reliability, and correlations among study variables.

\begin{tabular}{|c|c|c|c|c|c|c|c|c|c|c|c|c|c|c|c|c|c|c|c|}
\hline & & 1 & 2 & 3 & 4 & 5 & 6 & 7 & 8 & 9 & 10 & 11 & 12 & 13 & 14 & 15 & 16 & 17 & 18 \\
\hline 1 & MT & $(.86)$ & & & & & & & & & & & & & & & & & \\
\hline 2 & Goals-p & $.44 *$ & $(.73)$ & & & & & & & & & & & & & & & & \\
\hline 3 & Imag-p & $.33^{*}$ & $.53 *$ & $(.68)$ & & & & & & & & & & & & & & & \\
\hline 4 & Attcon-p & $.31 *$ & $.34 *$ & $.25^{*}$ & $(.89)$ & & & & & & & & & & & & & & \\
\hline 5 & Selftalk-p & $.36^{*}$ & $.65^{*}$ & $.52 *$ & $.35^{*}$ & $(.71)$ & & & & & & & & & & & & & \\
\hline 6 & Activate-p & $.37 *$ & $.44 *$ & $.30^{*}$ & $.38^{*}$ & $.44^{*}$ & $(.65)$ & & & & & & & & & & & & \\
\hline 7 & Emocon-p & $.16^{*}$ & -.05 & -.03 & $.39^{*}$ & .03 & $.24^{*}$ & (.69) & & & & & & & & & & & \\
\hline 8 & Auto-p & $.17^{*}$ & .12 & $.17^{*}$ & .00 & .08 & .10 & -.08 & $(.72)$ & & & & & & & & & & \\
\hline 9 & Relax-p & $.31 *$ & $.44^{*}$ & $.33^{*}$ & $.20^{*}$ & $.41 *$ & $.47^{*}$ & .03 & $.20^{*}$ & $(.77)$ & & & & & & & & & \\
\hline 10 & Goals-c & $.40^{*}$ & $.57 *$ & $.50 *$ & $.35^{*}$ & $.67 *$ & $.46^{*}$ & .05 & $.12 *$ & $.46^{*}$ & $(.82)$ & & & & & & & & \\
\hline 11 & Selftalk-c & $.38^{*}$ & $.62 *$ & $.53^{*}$ & $.42 *$ & $.70^{*}$ & $.46^{*}$ & .13 & .05 & $.38^{*}$ & $.65^{*}$ & $(.80)$ & & & & & & & \\
\hline 12 & Imag-c & $.41 *$ & $.57 *$ & $.57 *$ & $.38^{*}$ & $.65^{*}$ & $.50^{*}$ & .04 & $.16^{*}$ & $.45^{*}$ & $.62 *$ & $.63 *$ & $(.69)$ & & & & & & \\
\hline \multirow[t]{2}{*}{13} & Negthink-c & $-.24 *$ & $-.15^{*}$ & -.07 & - & - & - & - & .02 & -.05 & - & - & - & $(.78)$ & & & & & \\
\hline & & & & & $.48^{*}$ & $.24^{*}$ & $.34^{*}$ & $.38 *$ & & & $.26^{*}$ & $.31^{*}$ & $.27^{*}$ & & & & & & \\
\hline 14 & Emocon-c & $.19 *$ & .05 & $.12^{*}$ & $.40^{*}$ & .10 & $.16^{*}$ & $.54^{*}$ & -.06 & .03 & .04 & $.20 *$ & .11 & $-.43 *$ & $(.82)$ & & & & \\
\hline 15 & Activate-c & $.41 *$ & $.52 *$ & $.36^{*}$ & $.33^{*}$ & $.49 *$ & $.66^{*}$ & .11 & $.25^{*}$ & $.52 *$ & $.54^{*}$ & $.52 *$ & $.58^{*}$ & $-.28 *$ & .12 & $(.71)$ & & & \\
\hline 16 & Relax-c & $.35^{*}$ & $.52 *$ & $.33^{*}$ & $.34^{*}$ & $.49 *$ & $.53^{*}$ & .07 & $.18^{*}$ & $.58 *$ & $.53^{*}$ & $.52 *$ & $.53^{*}$ & $-.27 *$ & .03 & $.69^{*}$ & (.79) & & \\
\hline 17 & Auto-c & $.32 *$ & $.37 *$ & $.26^{*}$ & $.20^{*}$ & $.29 *$ & $.37 *$ & .05 & $.52 *$ & $.38^{*}$ & $.41^{*}$ & $.31 *$ & $.40^{*}$ & -.12 & -.03 & $.58^{*}$ & $.52 *$ & $(.65)$ & \\
\hline \multirow[t]{8}{*}{18} & Attcon-c & $.21 *$ & $.31 *$ & $.20 *$ & $.32 *$ & $.30 *$ & $.41^{*}$ & .11 & .01 & $.20 *$ & $.40 *$ & $.30 *$ & $.38^{*}$ & $-.25 *$ & .01 & $.44^{*}$ & $.40 *$ & $.35 *$ & $(.69)$ \\
\hline & Age & .05 & -.09 & .12 & .02 & .16 & -.09 & $.16^{*}$ & $.22 *$ & .02 & -.04 & .02 & -.02 & -.12 & -.14 & $.23^{*}$ & -.12 & -.07 & .06 \\
\hline & Experience & .01 & .20 & -.11 & -.10 & .02 & $.18^{*}$ & $\begin{array}{l}- \\
.15^{*}\end{array}$ & -.03 & -.06 & .08 & -.15 & .05 & -.06 & $.19 *$ & $\begin{array}{l}- \\
.29 *\end{array}$ & .15 & $.18^{*}$ & .08 \\
\hline & Sex & .03 & -.06 & -.06 & .03 & .01 & .03 & .04 & -.08 & .08 & .06 & -.07 & .09 & $.24 *$ & .03 & -.12 & -.01 & $.19 *$ & .04 \\
\hline & Mean & 5.83 & 3.69 & 3.74 & 3.39 & 3.75 & 3.40 & 3.06 & 3.05 & 3.45 & 3.81 & 3.90 & 3.72 & 2.53 & 3.19 & 3.58 & 3.62 & 3.46 & 3.26 \\
\hline & $S D$ & .83 & .64 & .71 & .55 & .62 & .54 & .58 & .61 & .68 & .65 & .68 & .61 & .80 & .74 & .61 & .69 & .62 & .42 \\
\hline & Skewness & -.91 & -.28 & -.20 & .23 & -.01 & .09 & .35 & -.39 & -.30 & -.16 & -.27 & -.29 & .35 & .05 & -.41 & -.18 & .08 & -.22 \\
\hline & Kurtosis & .91 & -.10 & -.37 & .21 & -.50 & .29 & .37 & 1.09 & .34 & -.14 & -.59 & .15 & -.25 & -.14 & .73 & .40 & -.05 & .21 \\
\hline
\end{tabular}

Note: $\mathrm{MT}=$ mental toughness; Goals- $\mathrm{p}=$ goal setting in practice; Imag- $\mathrm{p}=$ imagery in practice; Attcon- $\mathrm{p}=$ attention control in practice; Selftalk-p = self-talk in practice; Activate- $\mathrm{p}=$ activation in practice; Emocon- $\mathrm{p}=$ emotional control in practice; Auto- $\mathrm{p}=$ automaticity in practice; Relax-p = relaxation in practice; Goals-c = goal setting in competition; Selftalk-c $=$ self-talk in competition; Imag-c = imagery in competition; Negthink-c = negative thinking competition; Emocon-c = emotional control in competition;

Activate- $\mathrm{c}=$ activation in competition; Relax-c $=$ relaxation in competition; Auto-c $=$ automaticity in competition; Attcon-c $=$ attention control in competition; ${ }^{*} p<.05$. Readers interested in the $95 \%$ confidence intervals for these bivariate correlation can locate this information in the online supplementary material. 
Table 2 (on next page)

Model fit indices for all latent profile models tested. 
Table 2. Model fit indices for all latent profile models tested.

\begin{tabular}{|c|c|c|c|c|c|c|}
\hline & AIC & $\mathrm{BIC}$ & $\mathrm{ABIC}$ & $\begin{array}{l}\text { LMR LR test } \\
\text { p value }\end{array}$ & $\begin{array}{l}\text { ALMR LR } \\
\text { test } p \text { value }\end{array}$ & Entrophy \\
\hline & \multicolumn{6}{|c|}{ Practice Settings } \\
\hline 2-class & 3957.36 & 4048.67 & 3969.40 & .054 & .056 & .752 \\
\hline 3 -class & $3833.84(-3.22 \%)$ & $3958.03(-2.29 \%)$ & $3850.21(-3.09 \%)$ & .096 & .099 & .778 \\
\hline 4-class & $3810.54(-.61 \%)$ & $3967.60(.24 \%)$ & $3831.24(-.49 \%)$ & .373 & .379 & .787 \\
\hline 5-class & $3788.73(-.57 \%)$ & $3978.66(.28 \%)$ & $3813.76(-.45 \%)$ & .196 & .200 & .779 \\
\hline \multirow[t]{2}{*}{ 6-class } & $3770.64(-.48 \%)$ & $3993.44(.37 \%)$ & $3800.01(.36 \%)$ & .481 & .487 & .809 \\
\hline & \multicolumn{6}{|c|}{ Competition Settings } \\
\hline 2-class & 4420.40 & 4522.67 & 4433.88 & $<.001$ & $<.001$ & .858 \\
\hline 3-class & $4260.39(-3.76 \%)$ & $4399.19(-2.81 \%)$ & $4278.68(-3.63 \%)$ & .01 & .01 & .886 \\
\hline 4-class & $4189.00(-1.70 \%)$ & $4364.32(-.80 \%)$ & $4212.11(-1.58 \%)$ & .142 & .148 & .841 \\
\hline 5-class ${ }^{\#}$ & $4148.86(-.97 \%)$ & $4360.71(-.08 \%)$ & $4176.79(-.85 \%)$ & .167 & .17 & .867 \\
\hline 6-class ${ }^{\#}$ & $4108.06(-.99 \%)$ & $4356.43(-.10 \%)$ & $4140.80(-.87 \%)$ & 1 & 1 & .885 \\
\hline
\end{tabular}

Note: Number in parentheses for $\mathrm{AIC}, \mathrm{BIC}$ and $\mathrm{ABIC}=$ change value in percentage; $\mathrm{AIC}=$ Akaike Information Criteria; $\mathrm{BIC}=$ Bayesian Information Criteria; ABIC = sample size adjusted BIC; LMR LR test $=$ Lo-Mendell Rubin likelihood ratio test; ALMR LR $=$ Lo-Mendell Rubin adjusted likelihood ratio test; $\#=$ non-positive definite matrix. 


\section{Table 3 (on next page)}

Classification probabilities for the 2-4 profile solutions. 
1 Table 3. Classification probabilities for the 2-4 profile solutions.

2

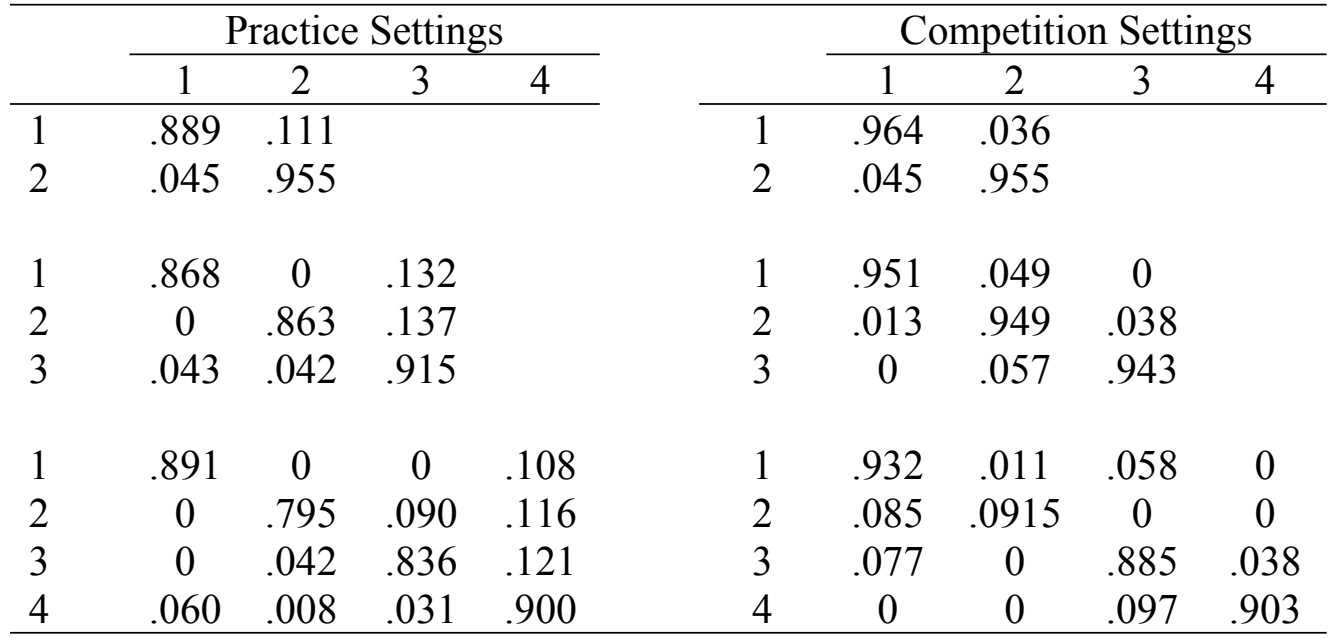

3

4 Note: The 5-profile and 6-profile solutions are omitted here due to a non-positive definite matrix. 5

6 


\section{Table 4 (on next page)}

Age, sex and years playing experience as determinants of latent profile membership. 
Table 4. Age, sex and years playing experience as determinants of latent profile membership.

\begin{tabular}{|c|c|c|c|c|}
\hline & \multicolumn{4}{|c|}{ Practice Settings } \\
\hline & & $\begin{array}{c}\text { High } \\
\text { adaptive use }\end{array}$ & $\begin{array}{c}\text { Moderate } \\
\text { adaptive use }\end{array}$ & $\begin{array}{c}\text { Low } \\
\text { adaptive use }\end{array}$ \\
\hline \multirow[t]{2}{*}{ Predictor } & Reference Class & & & \\
\hline & $\begin{array}{c}\text { High } \\
\text { adaptive use }\end{array}$ & & & \\
\hline Age $(n=250)$ & & & $.15(.05)^{* *}$ & $.04(.05)$ \\
\hline $\operatorname{Sex}(N=285)$ & & & $.25(.40)$ & $.27(.35)$ \\
\hline \multirow[t]{2}{*}{ Years playing experience $(n=230)$} & & & $.22(.07)^{* *}$ & $.11(.07)$ \\
\hline & $\begin{array}{c}\text { Moderate } \\
\text { adaptive use }\end{array}$ & & & \\
\hline Age $(n=250)$ & & $-.15 *(.05)^{* *}$ & & $-.11(.04) * *$ \\
\hline $\operatorname{Sex}(N=285)$ & & $-.25(.40)$ & & $.02(.39)$ \\
\hline \multirow[t]{3}{*}{ Years playing experience $(n=230)$} & & $-.22(.07)^{* *}$ & & $-.11(.05)^{*}$ \\
\hline & & Competitior & ettings & \\
\hline & & $\begin{array}{c}\text { High } \\
\text { adaptive use }\end{array}$ & $\begin{array}{c}\text { Moderate } \\
\text { adaptive use }\end{array}$ & $\begin{array}{c}\text { Low } \\
\text { adaptive use }\end{array}$ \\
\hline
\end{tabular}

\section{High}

Age $(\mathrm{n}=250)$

Sex $(N=285)$

Years playing experience $(\mathrm{n}=230)$

adaptive use

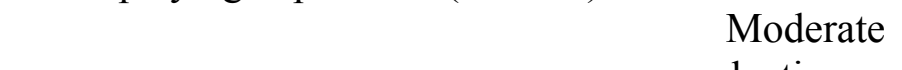

adaptive use

\begin{tabular}{lll} 
Age $(\mathrm{n}=250)$ & $-.07(.10)$ & $.08(.03)^{*}$ \\
Sex $(\mathrm{N}=285)$ & $-.99(.50)^{*}$ & $-.07(.29)$ \\
Years playing experience $(\mathrm{n}=230)$ & $-.06(.08)$ & $.05(.04)$ \\
\hline
\end{tabular}

3

4 Note: listwise deletion used for missing values on predictors; $* p<.05, * * p<.01, * * * p<.001$; standard errors are reported 5 parentheses. 


\section{Figure 1}

Estimated means for psychological skills and techniques used in practice as a function of class membership.

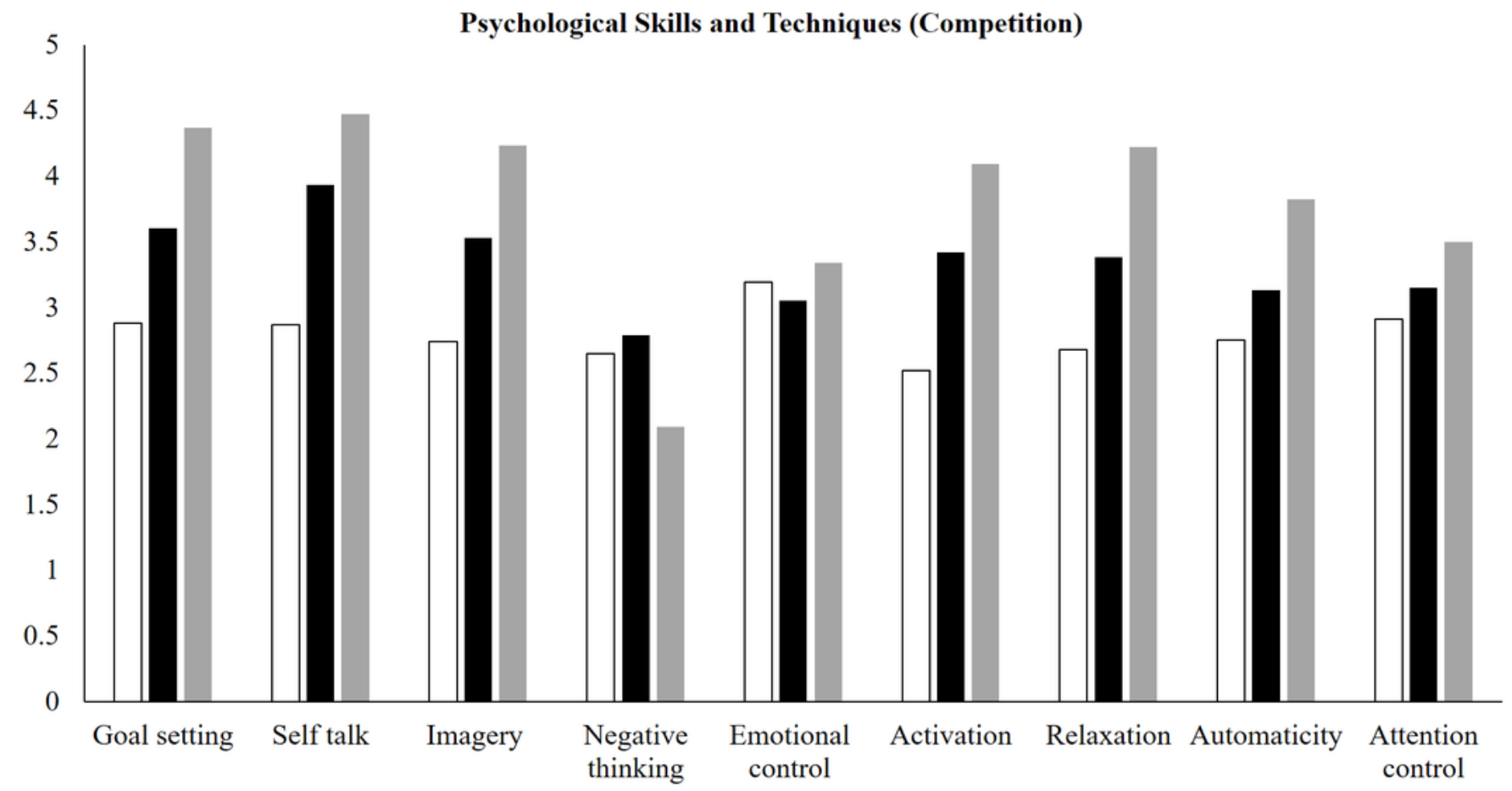

$\square$ Low Use $(\mathrm{n}=25) \quad$ Moderate Use $(\mathrm{n}=158) \quad$ High Use $(\mathrm{n}=102)$ 


\section{Figure 2}

Estimated means for psychological skills and techniques used in competition as a function of class membership.

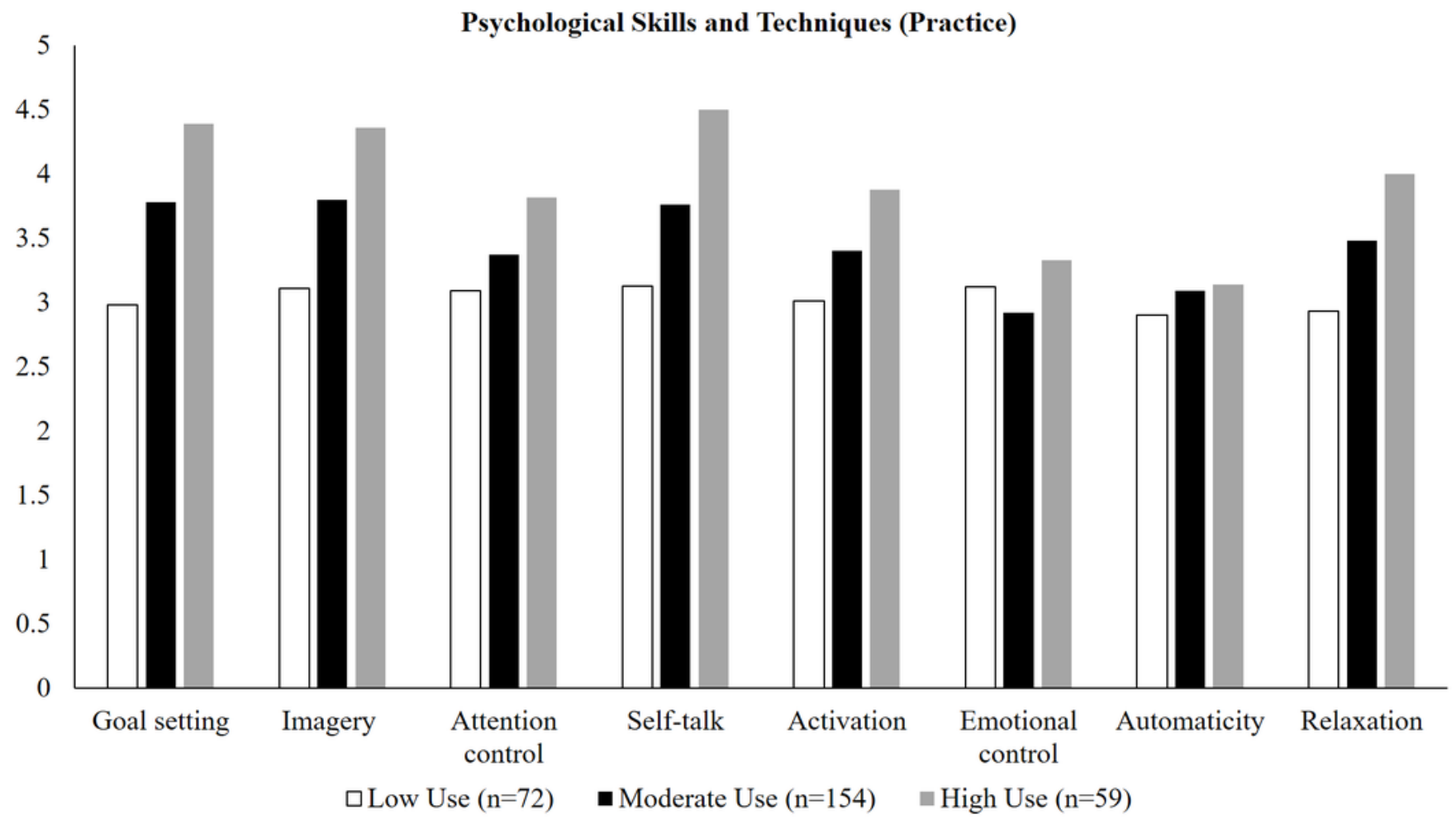

